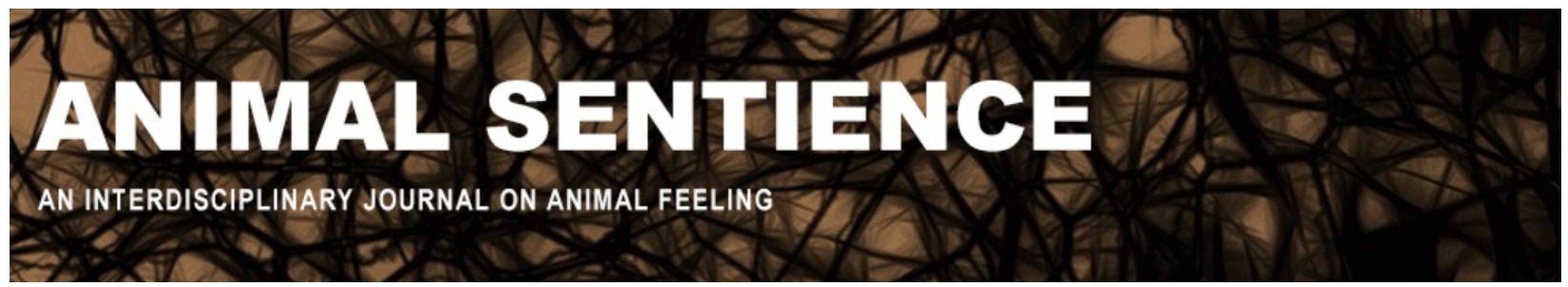

Siebeck, Ulrike E. (2017) Fish are flexible learners who can discriminate human faces. Animal Sentience 8(5)

DOI: $10.51291 / 2377-7478.1194$

Date of submission: 2017-02-17

Date of acceptance: 2017-02-22

(c)

This article has appeared in the journal Animal

Sentience, a peer-reviewed journal on animal

cognition and feeling. It has been made open access,

free for all, by WellBeing International and deposited

in the WBI Studies Repository. For more information,

please contact

wbisr-info@wellbeingintl.org.

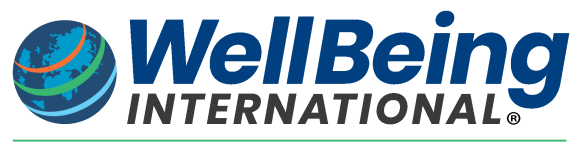

SOLUTIONS FOR PEOPLE, ANIMALS AND ENVIRONMENT 


\title{
Fish are flexible learners who can discriminate human faces
}

Commentary on Balcombe on Fish Knows

\author{
Ulrike E. Siebeck \\ Visual Neuroethology laboratory \\ University of Queensland, Australia
}

\begin{abstract}
In his book "What a fish knows" Jonathan Balcombe (2016a, b) has created a comprehensive profile of a group of animals still often thought to have a 3-second memory, no ability to feel pain, and a generally limited ability to learn. Chapter by chapter, Balcombe dismantles these and other such assumptions and makes a convincing case that fish have many abilities that are not that different from our own. Here, I focus on one example which supports the notion that fish are flexible learners and able to perform tasks which are generally thought to require the advanced processing power of the primate cortex. Archerfish and damselfish are able to discriminate human faces, even when the faces are partly obscured by artificial noise, rotated or presented as standardised greyscale images. This demonstrates that the machinery for the visual analysis and processing of objects is present in fish and leads to the question of why this machinery was transferred to the cortex in primates.
\end{abstract}

Keywords: visual learning, fish cognition, fish behaviour
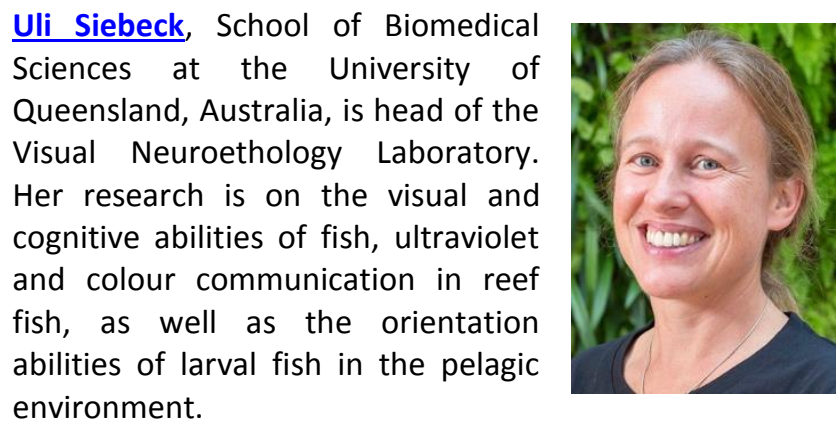

http://www.fisharesmart.net

I have spent a large portion of the last 15 years catching selected fish on the Great Barrier Reef and then training them to perform various tasks aimed at revealing their visual and cognitive abilities. It turns out that catching and training reef fish requires very good observational skills and what I call a good deal of "fish psychology." When pursuing fish underwater, new students often wave their hand nets around, wondering why they are not catching anything. Good students quickly learn that they have to sit back and watch each target fish for a while, and try to get into the fish's head. What habits do they exhibit? When do they go out, and where do they go? How many entrances are there to their hiding places, etc.? During these pursuits, there is almost always a time when the fish looks at you and you at the fish, each trying to predict the other's next movements. If all goes to plan, you can set up the net in a spot the fish uses as an escape route, move in, and catch the fish as it darts away into the net. If the fish escapes from the net, the same plan cannot be repeated, as the 
fish will change its strategy. What is more, the same plan does not work for all fish but has to be adapted individually depending on their individual responses to the diver's movements.

I have often wondered during this process of trying to outwit each other, what the fish are thinking. How do they evaluate the situation and come up with a new plan? It is very clear during these interactions that the behaviour of these fish is not based on hardwired reflexive actions but that they, much like us, are able to flexibly learn, develop strategies and predict the consequences of their actions. The general response of people to such suggestions is one of surprise or even disbelief. The general assumption still seems to be that fish don't have much of a memory and can't possibly be flexible learners. It is for this reason that I very much enjoyed reading Jonathan Balcombe's book (2016a, b), in which he has compiled evidence, anecdotes and personal experiences to create a portrait of fish that shows them as the feeling, thinking, learning creatures I have come to know over the years of studying them.

One of the reasons people think fish are simple animals is that they do not have a neocortex. In humans, abilities such as face recognition or feeling pain are intrinsically linked to the neocortex, a structure that fish lack. It is perhaps tempting to conclude from this that fish lack the commensurate abilities too. However, as demonstrated by various studies compiled in Balcombe's book, there is more and more evidence that fish do not just respond in a stereotypical way to noxious stimuli, but adapt their behaviour flexibly to try to alleviate what is clearly interpreted as an unpleasant sensation.

Intrigued by the ability of fish to quickly learn visual discrimination tasks, my fellow researchers and I decided to test whether they could discriminate human faces despite their lack of the cortical structures assumed to have evolved specifically for human face recognition. As mentioned by Balcombe, we started with archerfish, who can be trained to select an image presented on a monitor suspended above their holding tank by spitting at it. Initially, we trained them to an image of a face and tested whether they could identify the learned face when it was presented together with a second (unrewarded) face. They quickly learned this task irrespective of the position of the two images. By itself this may not be evidence for face recognition in fish, as they could solve this task by comparing cues such as the brightness or colour in part of the images. To control for this possibility, we standardised the brightness and shape (outline) of the faces, and found that this did not alter their ability to identify they had learned.

At this point it was still possible that the fish were using cues such as a local group of pixels that differed in brightness between the two images, so we added more distractor (unrewarded) faces. The fish now had to identify the learned face when it was randomly presented together with one of a group of up to 50 other faces. When the fish were still able to identify their target face, we concluded that they could indeed recognise human faces. The same process was repeated with different rewarded faces and different archerfish to show that there was nothing "special" about the original learned face. Taken together, these experiments demonstrate that archerfish can recognise human faces despite their lack of the cortical structures required for this task in humans.

Since we published the original paper describing these experiments, we have continued to investigate human face recognition in fish, using different species to test how widespread this ability may be. We have also tested rotated faces to see whether fish, like humans, can still recognise faces when they are rotated away from the frontal view. Everything points to the fact that fish discriminate human faces in a very similar way to us, and do so despite the lack of cortex and despite their visual system not having evolved to 
discriminate human faces. This leads to the conclusion, also discussed in Balcombe's book, that fish have invented many systems that we still rely on, in this case the basic processing structures for the discrimination of any objects. Rather than concluding that many abilities rely on the evolution of the cortex, these findings raise the questions about what led to the evolution of a cortex and why some processes were transferred to it.

I thoroughly recommend Balcombe's book to anyone interested in fish but also anyone interested in biological cognition, be it human or animal. His book provides a great overview of the current knowledge on fishes (with a useful reference list of the relevant studies); it is thought-provoking (with discussions on pain, consciousness, perception, etc.) and will inspire further research into these fascinating creatures.

While I might not agree with every conclusion the book wishes to draw, I strongly concur with the basic premise that fish are far more intelligent and feeling than we generally given them credit for. That's one reason, at the end of my field trips, I choose to return the fish to the sea.

\section{References}

Balcombe, J. (2016a). What a fish knows: The inner lives of our underwater cousins. New York: Farrar, Straus and Giroux.

Balcombe, J. (2016b). In praise of fishes: Précis of What a fish knows (Balcombe 2016). Animal Sentience, 8(1). 